\title{
Betatrophin levels are increased in women with gestational diabetes mellitus compared to healthy pregnant controls
}

\author{
Thomas Ebert ${ }^{1,2, *}$, Susan Kralisch ${ }^{1,2, *}$, Ulrike Wurst ${ }^{1,2}$, Ulrike Lössner ${ }^{1,2}$, \\ Jürgen Kratzsch ${ }^{3}$, Matthias Blüher ${ }^{1}$, Michael Stumvoll ${ }^{1}$, Anke Tönjes ${ }^{1,2}$ and \\ Mathias Fasshauer ${ }^{1,2}$ \\ ${ }^{1}$ Department of Endocrinology and Nephrology, University of Leipzig, Liebigstraße 20, 04103 Leipzig, Germany، \\ ${ }^{2}$ Leipzig University Medical Center, IFB AdiposityDiseases, Liebigstraße 20, 04103 Leipzig, Germany and \\ ${ }^{3}$ Institute of Laboratory Medicine, University of Leipzig, Leipzig, Germany \\ *(T Ebert and S Kralisch contributed equally to this work)
}

\section{Abstract}

Objective: Betatrophin has recently been introduced as a novel adipokine/hepatokine, which promotes pancreatic $\beta$ cell proliferation and improves glucose tolerance in several mouse models of insulin resistance. However, regulation of betatrophin in gestational diabetes mellitus (GDM), as well as its association with markers of obesity, such as glucose and lipid metabolism, inflammation, and renal function, have not been elucidated.

Design and methods: Circulating betatrophin was quantified in 74 women with GDM and 74 healthy and gestational age-matched controls by ELISA. In a subset of the study population comprising of 85 patients ( 41 previous controls, 44 previous women with GDM), postpartum betatrophin levels were measured in a follow-up study. Results: Median (interquartile range) serum betatrophin levels were higher in women with GDM (1.79 (0.53) $\mu \mathrm{g} / \mathrm{l})$ as compared to non-diabetic pregnant controls $(1.58(0.44) \mu \mathrm{g} / \mathrm{l})(P=0.002)$. In multivariate analysis, GDM status was an independent and positive predictor of circulating betatrophin $(P=0.001)$. Furthermore, betatrophin levels were significantly higher during gestation $(1.70(0.53) \mu \mathrm{g} / \mathrm{l})$ as compared to postpartum levels $(1.55(0.66) \mu \mathrm{g} / \mathrm{l})(P=0.028)$. Moreover, postpartum irisin remained a positive and independent predictor of postpartum betatrophin concentrations. Conclusions: Women with GDM have significantly higher betatrophin levels as compared to healthy pregnant controls and GDM status positively predicts circulating betatrophin. Furthermore, postpartum levels are significantly lower as compared to betatrophin concentrations during pregnancy. Moreover, irisin is a significant predictor of postpartum betatrophin levels.

\section{Introduction}

Gestational diabetes mellitus (GDM) is a metabolic disorder during pregnancy leading to acute and chronic complications in both mother and newborn. Interestingly, GDM shares several risk factors with type 2 diabetes mellitus (T2DM), suggesting a potential link between these two metabolic disease states. However, the exact pathogenesis of GDM has not been fully understood, yet. In the past few years, a dysregulation of various adipocyte- and hepatocyte-derived factors, including adiponectin, leptin, fibroblast growth factor (FGF) 21, and adipocyte fatty acid-binding protein, has been reported to mediate insulin resistance and proinflammatory effects in both T2DM (1) and $\operatorname{GDM}(2,3,4)$.

Recently, betatrophin (also known as hepatocellular carcinoma-associated protein TD26, lipasin, refeeding induced fat and liver, or angiopoietin-like protein 8) has

Published by Bioscientifica Ltd. 
been introduced as a novel adipokine/hepatokine, which significantly and specifically promotes pancreatic $\beta$ cell proliferation, expands $\beta$ cell mass, and improves glucose tolerance in mouse models of insulin resistance (5). In their study, Yi et al. (5) suggested that betatrophin could potentially limit adverse metabolic status in severe insulin resistance by increasing $\beta$ cell proliferation. Interestingly, serum levels of this $\beta$ cell effector are doubled in patients with type 1 diabetes mellitus (T1DM) as compared to age-matched healthy controls in a very recent study (6). Furthermore, Fenzl et al. (7) demonstrated that the novel adipokine/hepatokine correlates significantly with an atherogenic lipid profile in small cohorts comprising of patients with morbid obesity or T2DM.

However, data on betatrophin regulation in humans so far is limited to patients with T1DM (6), morbid obesity (8), or T2DM $(7,8,9)$, and there are no studies investigating betatrophin in GDM. Since betatrophin could potentially counteract impaired glucose control seen in GDM by improving $\beta$ cell proliferation (5), our rationale was to investigate this novel adipokine/ hepatokine and its potential associations with other metabolic markers in human GDM. Therefore, we determined circulating betatrophin concentrations in 74 well-phenotyped women with GDM during pregnancy as compared to 74 gestational age-matched, healthy pregnant controls. Furthermore, we measured postpartum betatrophin serum levels in a subset of these 148 women comprising 85 women. Moreover, we correlated betatrophin to clinical and biochemical measures of renal function, indices of glucose metabolism, lipid metabolism, as well as inflammation.

We hypothesized that the adipokine/hepatokine is increased in GDM as compared to non-diabetic and healthy women.

\section{Subjects and methods}

\section{Study participants}

For this cross-sectional study, 148 pregnant patients were recruited from the outpatient care unit of the Department of Endocrinology and Nephrology, University of Leipzig between 2006 and 2011. The study design has recently been described $(10,11)$. In brief, a $75 \mathrm{~g}, 2 \mathrm{~h}$ oral glucose tolerance test (OGTT) was performed in all participants according to the criteria of the American Diabetes Association (12). GDM was diagnosed if one or more plasma glucose levels were elevated during the OGTT using the following threshold plasma glucose levels: fasting $\quad \geq 5.1 \mathrm{mmol} / \mathrm{l} ; \quad 1 \mathrm{~h} \quad \geq 10.0 \mathrm{mmol} / \mathrm{l} ; \quad 2 \mathrm{~h}$ $\geq 8.5 \mathrm{mmol} / \mathrm{l}$. Based on these thresholds, 74 pregnant subjects were classified as GDM patients. Furthermore, 74 gestational age-matched pregnant women with normal glucose tolerance served as controls. To investigate postpartum regulation of this novel adipokine/hepatokine, all women were invited to take part in a follow-up study in 2012. A total of 85 patients (41 previous controls, 44 previous GDM) were available for follow-up (median time after delivery: 1576 days). BMI was determined as weight before gestation divided by squared height. Furthermore, homeostasis model assessment of insulin resistance (HOMA-IR) and $\beta$-cell function (HOMA-B) were determined as described in (13). The study was approved

Table 1 Baseline characteristics of the study population during pregnancy. Values for median (interquartile range) are shown.

\begin{tabular}{|c|c|c|c|}
\hline & Controls & GDM & $\boldsymbol{P}$ \\
\hline$n$ & 74 & 74 & \\
\hline Betatrophin $(\mu \mathrm{g} / \mathrm{l})$ & $1.58(0.44)$ & $1.79(0.53)$ & $0.002 *$ \\
\hline Age (years) & $28.9(4.5)$ & $31.0(7.5)$ & 0.087 \\
\hline $\begin{array}{l}\text { Gestational age at blood } \\
\text { sampling (days) }\end{array}$ & $199(40)$ & $202(33)$ & 0.568 \\
\hline $\begin{array}{l}\text { Gestational age at } \\
\text { delivery (days) }\end{array}$ & $275(15)$ & $273(14)$ & 0.312 \\
\hline Infant birth weight (g) & $3360(790)$ & $3400(805)$ & 0.471 \\
\hline BMI $\left(\mathrm{kg} / \mathrm{m}^{2}\right)$ & $22.4(6.7)$ & $24.5(6.6)$ & 0.117 \\
\hline $\mathrm{SBP}(\mathrm{mmHg})$ & $125(17)$ & $120(20)$ & 0.338 \\
\hline $\mathrm{DBP}(\mathrm{mmHg})$ & 75 (13) & $73(15)$ & 0.349 \\
\hline $\mathrm{HbA1c}(\%)$ & $5.3(0.6)$ & $5.4(0.6)$ & 0.729 \\
\hline $\mathrm{HbA} 1 \mathrm{c}(\mathrm{mmol} / \mathrm{mol})$ & $34.4(6.6)$ & $35.5(6.6)$ & 0.729 \\
\hline Glucose $0 \mathrm{~h}_{(\mathrm{OGTT})}(\mathrm{mmol} / \mathrm{l})$ & $4.3(0.5)$ & $4.5(0.9)$ & $<0.001 *$ \\
\hline Glucose $1 \mathrm{~h}_{(\mathrm{OGTT})}(\mathrm{mmol} / \mathrm{l})$ & $7.5(1.6)$ & $10.1(1.7)$ & $<0.001 *$ \\
\hline Glucose $2 \mathrm{~h}_{(\mathrm{OGTT})}(\mathrm{mmol} / \mathrm{l})$ & $6.4(1.8)$ & $8.7(2.3)$ & $<0.001 *$ \\
\hline $\mathrm{FI}(\mathrm{pmol} / \mathrm{l})$ & $57.9(38.4)$ & $70.6(66.7)$ & $0.003 *$ \\
\hline HOMA-IR & $1.57(0.97)$ & $1.99(1.90)$ & $<0.001 *$ \\
\hline HOMA-B (\%) & $204.2(183.0)$ & $209.6(219.0)$ & 0.853 \\
\hline GlucoseAUC & $12.7(2.4)$ & $16.6(2.1)$ & $<0.001 *$ \\
\hline Cholesterol $(\mathrm{mmol} / \mathrm{l})$ & $6.31(1.84)$ & $6.71(1.74)$ & 0.199 \\
\hline HDL cholesterol (mmol/l) & $1.93(0.51)$ & $1.82(0.80)$ & 0.419 \\
\hline LDL cholesterol (mmol/l) & $3.73(1.57)$ & $4.05(1.91)$ & 0.569 \\
\hline TG (mmol/l) & $2.02(1.43)$ & $2.14(1.31)$ & 0.453 \\
\hline FFA $(\mathrm{mmol} / \mathrm{l})$ & $0.47(0.30)$ & $0.55(0.31)$ & $0.047 *$ \\
\hline Creatinine $(\mu \mathrm{mol} / \mathrm{l})$ & $49.0(11.0)$ & $46.0(11.3)$ & 0.086 \\
\hline hsCRP (mg/l) & $4.20(4.30)$ & 3.99 (6.09) & 0.903 \\
\hline Leptin (mg/l) & $23.0(11.9)$ & $26.5(21.6)$ & 0.131 \\
\hline Adiponectin (mg/l) & $7.0(3.8)$ & $6.7(4.4)$ & 0.486 \\
\hline Irisin $(\mu \mathrm{g} / \mathrm{l})$ & $466.6(178.0)$ & $482.1(132.1)$ & 0.340 \\
\hline
\end{tabular}

BMI, body mass index; DBP, diastolic blood pressure; FFA, free fatty acids $\mathrm{FI}$, fasting insulin; GDM, gestational diabetes mellitus; GlucoseAUC, area under the glucose curve; HOMA-B, homeostasis model assessment of $\beta$-cell function; HOMA-IR, homeostasis model assessment of insulin resistance; hsCRP, high sensitivity $C$ reactive protein; OGTT, oral glucose tolerance test; $\mathrm{SBP}$, systolic blood pressure; TG, triglycerides. ${ }^{*} P<0.05$ as assessed by Mann-Whitney $U$ test. 
by the local Ethics Committee and all subjects gave written informed consent before taking part.

\section{Assays}

All blood samples at both time points, i.e. during pregnancy and postpartum, were obtained in a post-absorptive state after an at least $8 \mathrm{~h}$ fasting period in the morning. Betatrophin and irisin (Phoenix Pharmaceuticals, Burlingame, CA, USA), as well as adiponectin and leptin (Mediagnost, Reutlingen, Germany), serum concentrations were determined with an ELISA according to the manufacturers' instructions. Fasting insulin (FI) was determined with a two-site chemiluminescent enzyme immunometric assay for the LIAISON automated analyzer (DiaSorin, Saluggia, Italy). Furthermore, HbA1c, glucose levels during OGTT, total cholesterol, HDL cholesterol, LDL cholesterol, triglycerides (TG), free fatty acids (FFA), were measured by standard laboratory methods in a certified laboratory.

\section{Statistical analysis}

SPSS Software version 20.0 (IBM, Armonk, NY, USA) was used in all statistical analyses. Differences between women with GDM and controls during and after pregnancy were assessed by non-parametric Mann-Whitney $U$ test. Differences in circulating betatrophin during pregnancy and postpartum were assessed by non-parametric Wilcoxon signed rank test. Univariate correlations were performed using non-parametric Spearman's rank correlation method. Afterward, multivariate linear regression analysis was performed to identify independent relationships. Before multivariate correlation analyses were calculated, distribution of the respective variables was tested for normality using Shapiro-Wilk $W$ test and non-normally distributed parameters were logarithmically transformed.

Table 2 Univariate correlations and multivariate regression analysis during pregnancy. Univariate correlations with betatrophin, as well as multivariate regression analysis between betatrophin (lg) (dependent variable) and age (lg), GDM status, HDL cholesterol, and leptin (lg) in all women during pregnancy. Non-normally distributed variables were logarithmically transformed (lg) prior to multivariate testing. $r$ and $P$ values, as well as standardized $\beta$ and $P$ values are given, respectively.

\begin{tabular}{|c|c|c|c|c|}
\hline & \multicolumn{2}{|c|}{ Univariate correlations } & \multicolumn{2}{|c|}{ Multivariate analysis } \\
\hline & $r$ & $P$ & $\beta$ & $P$ \\
\hline Age (years) & -0.090 & 0.278 & -0.189 & $0.017 *$ \\
\hline GDM status & - & - & 0.263 & $0.001 *$ \\
\hline Gestational age at blood sampling (days) & -0.033 & 0.693 & - & - \\
\hline Gestational age at delivery (days) & -0.009 & 0.917 & - & - \\
\hline Infant birth weight $(\mathrm{g})$ & -0.039 & 0.652 & - & - \\
\hline $\mathrm{BMI}\left(\mathrm{kg} / \mathrm{m}^{2}\right)$ & -0.004 & 0.958 & - & - \\
\hline SBP $(\mathrm{mmHg})$ & 0.059 & 0.484 & - & - \\
\hline $\mathrm{DBP}(\mathrm{mmHg})$ & 0.118 & 0.166 & - & - \\
\hline $\operatorname{HbA1c}(\%)$ & -0.022 & 0.792 & - & - \\
\hline $\mathrm{HbA} 1 \mathrm{c}(\mathrm{mmol} / \mathrm{mol})$ & -0.022 & 0.792 & - & - \\
\hline Glucose $0 \mathrm{~h}_{\text {(OGTT) }}(\mathrm{mmol} / \mathrm{l})$ & 0.116 & 0.159 & - & - \\
\hline Glucose $1 \mathrm{~h}_{\text {(OGTT) }}(\mathrm{mmol} / \mathrm{l})$ & 0.146 & 0.086 & - & - \\
\hline Glucose $2 \mathrm{~h}_{\text {(OGTI) }}(\mathrm{mmol} / \mathrm{l})$ & 0.135 & 0.114 & - & - \\
\hline $\mathrm{FI}(\mathrm{pmol} / \mathrm{l})$ & 0.072 & 0.384 & - & - \\
\hline HOMA-IR & 0.087 & 0.295 & _- & _- \\
\hline HOMA-B (\%) & 0.022 & 0.794 & - & - \\
\hline GlucoseAUC & 0.159 & 0.061 & _- & _- \\
\hline Cholesterol (mmol/l) & 0.103 & 0.214 & - & - \\
\hline HDL cholesterol (mmol/l) & 0.272 & 0.001 * & 0.279 & $<0.001 *$ \\
\hline LDL cholesterol (mmol/l) & 0.070 & 0.398 & - & - \\
\hline TG $(\mathrm{mmol} / \mathrm{l})$ & -0.114 & 0.166 & - & - \\
\hline $\mathrm{FFA}(\mathrm{mmol} / \mathrm{l})$ & -0.019 & 0.820 & - & - \\
\hline Creatinine $(\mu \mathrm{mol} / \mathrm{l})$ & -0.018 & 0.825 & - & - \\
\hline hsCRP (mg/l) & 0.011 & 0.892 & - & - \\
\hline Leptin (mg/l) & 0.256 & $0.002 *$ & 0.150 & 0.052 \\
\hline Adiponectin (mg/l) & 0.057 & 0.495 & - & - \\
\hline Irisin $(\mu \mathrm{g} / \mathrm{l})$ & 0.091 & 0.272 & - & - \\
\hline
\end{tabular}

Abbreviations are indicated in Table 1. ${ }^{\star} P<0.05$ in univariate, as well as multivariate analysis, respectively. 
A $P$ value of $<0.05$ was considered as statistically significant in all analyses.

\section{Results}

\section{Baseline characteristics of the entire cohort during pregnancy}

Median (interquartile range) serum betatrophin in the total sample during pregnancy was 1.69 (0.52) $\mu \mathrm{g} / \mathrm{l}$. Clinical characteristics of the subgroups studied (controls, GDM) during pregnancy are shown in Table 1. Median serum betatrophin levels during pregnancy were significantly higher in women with GDM (1.79 (0.53) $\mu \mathrm{g} / \mathrm{l})$ compared to controls $(1.58(0.44) \mu \mathrm{g} / \mathrm{l})(P=0.002)$ (Table 1$)$. Furthermore, plasma glucose levels during OGTT, FI, HOMA-IR, area under the glucose curve, and FFA were significantly higher in women with GDM as compared to controls $(P<0.05)$ (Table 1$)$. In matched prepartum and postpartum samples, circulating betatrophin during pregnancy (1.70 $(0.53) \mu \mathrm{g} / \mathrm{l})$ was significantly higher compared to postpartum levels $(1.55(0.66) \mu \mathrm{g} / \mathrm{l})(P=0.028)$.

Table 3 Baseline characteristics in the follow-up study (postpartum). Values for median (interquartile range) are shown.

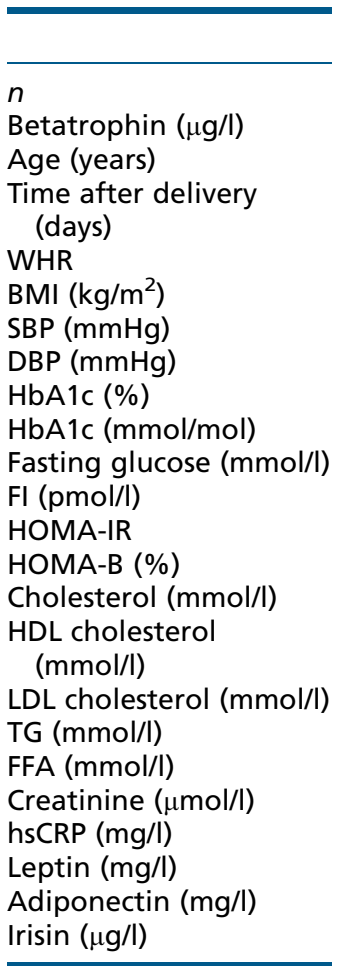

\begin{tabular}{|c|c|c|}
\hline Controls & GDM & $\boldsymbol{P}$ \\
\hline 41 & 44 & \\
\hline $1.52(0.60)$ & $1.61(0.74)$ & 0.077 \\
\hline $34.5(8.8)$ & $36.1(7.5)$ & 0.791 \\
\hline 1606.5 (207) & 1513 (709) & 0.092 \\
\hline $0.88(0.08)$ & $0.85(0.11)$ & 0.114 \\
\hline 23.5 (4.9) & $25.2(5.5)$ & 0.645 \\
\hline 115 (18) & $120(15)$ & 0.125 \\
\hline 75 (18) & 80 (15) & 0.081 \\
\hline $5.0(0.2)$ & $5.0(0.4)$ & 0.329 \\
\hline 30.9 (2.3) & $31.0(3.8)$ & 0.329 \\
\hline $4.8(0.4)$ & $4.9(0.6)$ & 0.138 \\
\hline $54.4(63.9)$ & $64.3(41.9)$ & 0.705 \\
\hline $1.56(1.94)$ & $1.85(1.30)$ & 0.627 \\
\hline $131.0(134.4)$ & $109.4(110.4)$ & 0.710 \\
\hline $4.92(1.01)$ & $5.20(1.37)$ & 0.062 \\
\hline $1.60(0.42)$ & $1.61(0.52)$ & 0.859 \\
\hline $2.91(0.92)$ & $3.20(1.32)$ & 0.117 \\
\hline $0.89(0.60)$ & $1.11(0.70)$ & 0.206 \\
\hline $0.42(0.28)$ & $0.55(0.34)$ & 0.195 \\
\hline $67.0(16.5)$ & $65.0(14.5)$ & 0.956 \\
\hline $1.56(3.60)$ & $1.11(4.71)$ & 0.718 \\
\hline $10.9(14.4)$ & $13.6(21.6)$ & 0.725 \\
\hline $6.6(3.4)$ & $7.4(3.4)$ & 0.250 \\
\hline $378.0(111.4)$ & 446.3 (146.9) & $0.001 *$ \\
\hline
\end{tabular}

Abbreviations are indicated in Table $1 .{ }^{\star} P<0.05$ as assessed by MannWhitney $U$ test.

\section{Univariate correlations during pregnancy}

Betatrophin positively correlated with HDL cholesterol and leptin in univariate analysis $(P<0.05$; Table 2$)$. In contrast, no significant correlations could be established between serum betatrophin and blood pressure, markers of glucose tolerance including FI, fasting glucose, HOMA-IR, HOMA-B, area under the glucose curve, renal function, inflammation, as well as the adipokines adiponectin and irisin, in the total sample (Table 2).

\section{Multivariate regression analysis during pregnancy}

To verify independent associations, multiple linear regression analysis was performed. Here, GDM status remained a positive, independent, and significant predictor of betatrophin serum levels ( $P=0.001$; Table 2$)$. Furthermore, the adipokine/hepatokine was significantly and positively associated with HDL cholesterol $(P<0.001)$ whereas a negative association was observed with patient age $(P=0.017)$ (Table 2$)$.

\section{Baseline characteristics of the postpartum follow-up cohort}

Median (interquartile range) serum betatrophin in the postpartum follow-up cohort was $1.55(0.66) \mu \mathrm{g} / \mathrm{l}$. Clinical characteristics of the follow-up subcohort are shown in Table 3. Postpartum betatrophin concentrations were not significantly different in women with prior GDM (1.61 (0.74) $\mu \mathrm{g} / \mathrm{l})$ compared to the control group (1.52 (0.60) $\mu \mathrm{g} / \mathrm{l})(P=0.077)$ (Table 3).

\section{Univariate correlations and multivariate regression analysis in the postpartum follow-up cohort}

Betatrophin positively correlated with time after delivery, HDL cholesterol, hsCRP, and irisin in univariate analysis $(P<0.05$; Table 4). Multiple linear regression analysis revealed that irisin remained a positive, independent, and significant predictor of betatrophin serum levels $(P=0.047$; Table 4). In contrast, betatrophin was not significantly associated with markers of glucose tolerance including FI, fasting glucose, HOMA-IR, and HOMA-B (Table 4).

\section{Discussion}

In the current study, we show for the first time that patients with GDM have increased betatrophin serum 
Table 4 Univariate correlations and multivariate regression analysis in the follow-up study (postpartum). Univariate correlations with betatrophin, as well as multivariate regression analysis between betatrophin (lg) (dependent variable) and age, GDM status, time after delivery (lg), HDL cholesterol, hsCRP (lg), and irisin (lg), in the follow-up study (postpartum). Non-normally distributed variables were logarithmically transformed $(\mathrm{lg})$ prior to multivariate testing. $r$ and $P$ values, as well as standardized $\beta$ and $P$ values, are given, respectively.

\begin{tabular}{|c|c|c|c|c|}
\hline & \multicolumn{2}{|c|}{ Univariate correlations } & \multicolumn{2}{|c|}{ Multivariate analysis } \\
\hline & $r$ & $P$ & $\beta$ & $P$ \\
\hline Age (years) & 0.032 & 0.773 & 0.006 & 0.955 \\
\hline GDM status & - & - & 0.197 & 0.089 \\
\hline Time after delivery (days) & 0.245 & $0.024 *$ & 0.196 & 0.128 \\
\hline WHR & 0.086 & 0.435 & - & - \\
\hline BMI $\left(k g / m^{2}\right)$ & 0.118 & 0.288 & - & - \\
\hline $\mathrm{SBP}(\mathrm{mmHg})$ & 0.005 & 0.962 & - & - \\
\hline DBP $(\mathrm{mmHg})$ & 0.041 & 0.712 & - & - \\
\hline $\mathrm{HbA1c}(\%)$ & -0.152 & 0.166 & - & - \\
\hline $\mathrm{HbA} 1 \mathrm{c}(\mathrm{mmol} / \mathrm{mol})$ & -0.152 & 0.166 & - & - \\
\hline Fasting glucose (mmol/l) & -0.089 & 0.420 & - & - \\
\hline $\mathrm{FI}(\mathrm{pmol} / \mathrm{l})$ & 0.069 & 0.532 & - & - \\
\hline HOMA-IR & 0.048 & 0.664 & - & - \\
\hline HOMA-B (\%) & 0.106 & 0.333 & - & - \\
\hline Cholesterol (mmol/l) & 0.086 & 0.431 & - & - \\
\hline HDL cholesterol (mmol/l) & 0.226 & $0.038 *$ & 0.165 & 0.135 \\
\hline LDL cholesterol (mmol/l) & -0.029 & 0.796 & - & - \\
\hline TG $(\mathrm{mmol} / \mathrm{l})$ & 0.190 & 0.082 & - & - \\
\hline FFA (mmol/l) & 0.037 & 0.739 & - & - \\
\hline Creatinine $(\mu \mathrm{mol} / \mathrm{l})$ & -0.138 & 0.207 & - & - \\
\hline hsCRP (mg/l) & 0.241 & 0.026 * & 0.123 & 0.305 \\
\hline Leptin (mg/l) & 0.157 & 0.151 & - & - \\
\hline Adiponectin (mg/l) & 0.056 & 0.736 & - & - \\
\hline Irisin $(\mu \mathrm{g} / \mathrm{l})$ & 0.323 & $0.003 *$ & 0.262 & $0.047 *$ \\
\hline
\end{tabular}

Abbreviations are indicated in Table 1. ${ }^{*} P<0.05$ in univariate, as well as multivariate analysis, respectively.

levels as compared to healthy pregnant controls. Furthermore, GDM status remains a positive and independent predictor of circulating betatrophin during pregnancy. Moreover, we also show for the first time that the postpartum betatrophin is significantly lower as compared to prepartal concentrations. In addition, irisin is an independent and positive predictor of betatrophin in the postpartum state. This is in accordance with results from Zhang et al. (14) demonstrating that treatment of adipocytes with recombinant irisin significantly increases expression of betatrophin in 3T3-L1 adipocytes in vitro. The major source of increased circulating betatrophin concentrations in women with GDM needs to be established in future experiments. In this context, it is interesting to note that betatrophin mRNA expression in the liver is upregulated three- to sixfold in S961-treated animals, ob/ob, as well as db/db mice (5). Furthermore, the same group convincingly demonstrates that hepatic betatrophin mRNA production in mice increases during pregnancy (5). Moreover, two recent papers reveal that betatrophin is only minimally expressed in human and mouse placenta tissue $(5,15)$. Taking these findings and our data into consideration, a hepatic rather than a placental origin seems to be responsible for the observed and transiently upregulation of betatrophin in GDM in our present cohort.

The physiological significance of increased betatrophin levels in patients with GDM remains to be determined. In this context, it is interesting to note that mice injected with plasmids encoding betatrophin have a 17 -fold increase in $\beta$ cell replication as compared to control animals (5). Yi et al. (5) suggest that this effect is mediated by altered expression of several cell cycle regulators in islets, including several cyclins, cyclindependent kinases, E2F transcription factors, as well as several cell-cycle inhibitors. Taking these results into consideration, it is tempting to speculate that increased circulating betatrophin in GDM counteracts metabolic dysfunction. Alternatively, GDM might be a betatrophinresistant state with concomitant upregulation of the adipokine/hepatokine. In this context, it is interesting to note that for other adipokines/hepatokines, including 
leptin (16) and FGF-21 (17) resistance has been shown in obesity-associated disease states. Clearly, these hypotheses need to be addressed in future studies. Furthermore, the physiological role and regulation of betatrophin in normal pregnancy should be established.

Besides GDM status, betatrophin is directly and independently associated with HDL cholesterol in multivariate analysis in the present study. In this context, it is interesting to note that a nonsynonymous variant in the betatrophin gene affects plasma levels of LDL and HDL cholesterol without influencing TG (15). Furthermore, a trend $(P=0.052)$ towards a positive association between betatrophin and leptin is shown in multivariate analysis in the present study. In contrast to our findings, Fenzl et al. (7) demonstrate a correlation between the novel adipokine/hepatokine and an atherogenic lipid profile including total and LDL cholesterol, as well as apo-lipoprotein B, in patients with morbid obesity and T2DM but not in controls. Moreover, no association between circulating betatrophin on one hand and HDL cholesterol or leptin on the other hand has been found in 33 non-pregnant patients with T1DM (6). Clearly, additional work in larger pregnant and non-pregnant patient samples is necessary before more definite conclusions can be reached.

In conclusion, women with GDM have significantly higher betatrophin levels as compared to healthy pregnant controls and GDM status positively predicts circulating betatrophin. Furthermore, postpartum levels are significantly lower as compared to betatrophin concentrations during pregnancy, suggesting a hepatic upregulation of this novel adipokine/hepatokine in pregnancy. Moreover, irisin is a significant predictor of postpartum betatrophin. Further studies need to elucidate factors contributing to betatrophin regulation in humans as well as the pathophysiological significance of betatrophin upregulation in GDM.

\section{Declaration of interest}

The authors declare that there is no conflict of interest that could be perceived as prejudicing the impartiality of the research reported.

\section{Funding}

This study was supported by grants to $M$ Fasshauer from the Deutsche Forschungsgemeinschaft (DFG, SFB 1052/1, C06), the Federal Ministry of Education and Research (BMBF), Germany, FKZ: $01 E 01001$ (IFB AdiposityDiseases, projects K7-3, K7-9, K7-58, and K7-31), and the Deutsche Hochdruckliga e.V., as well as grants to $\mathrm{S}$ Kralisch and T Ebert from the German Diabetes Association (DDG). Furthermore, T Ebert was supported by the Federal Ministry of Education and Research (BMBF), Germany, FKZ: $01 \mathrm{EO} 1001$ (IFB AdiposityDiseases, MetaRot program) and by an MSD grant
(MSD Stipendium 2013 Diabetologie). Moreover, A Tönjes was supported by grants from the DFG (SFB 1052/1, C01 and SPP 1629 TO 718/2-1), DDG, and DHFD (Diabetes Hilfs- und Forschungsfonds Deutschland).

\section{Author contribution statement}

T Ebert, S Kralisch, and M Fasshauer wrote the manuscript and researched data. U Wurst and J Kratzsch researched data and reviewed/edited the manuscript. U Lössner researched data. M Blüher, M Stumvoll, and A Tönjes contributed to the discussion and reviewed/edited the manuscript.

\section{References}

1 Fasshauer M \& Paschke R. Regulation of adipocytokines and insulin resistance. Diabetologia 200346 1594-1603. (doi:10.1007/ s00125-003-1228-z)

2 Kralisch S, Stepan H, Kratzsch J, Verlohren M, Verlohren H-J, Drynda K, Lössner U, Blüher M, Stumvoll M \& Fasshauer M. Serum levels of adipocyte fatty acid binding protein are increased in gestational diabetes mellitus. European Journal of Endocrinology 2009160 33-38. (doi:10.1530/EJE-08-0540)

3 Miehle K, Stepan H \& Fasshauer M. Leptin, adiponectin and other adipokines in gestational diabetes mellitus and pre-eclampsia. Clinical Endocrinology 201276 2-11. (doi:10.1111/j.1365-2265.2011.04234.x)

4 Fasshauer M, Blüher M \& Stumvoll M. Adipokines in gestational diabetes. Lancet. Diabetes \& Endocrinology 20142 488-499. (doi:10.1016/ S2213-8587(13)70176-1)

5 Yi P, Park J-S \& Melton DA. Betatrophin: a hormone that controls pancreatic $\beta$ cell proliferation. Cell 2013153 747-758. (doi:10.1016/ j.cell.2013.04.008)

6 Espes D, Lau J \& Carlsson P-O. Increased circulating levels of betatrophin in individuals with long-standing type 1 diabetes. Diabetologia 201457 50-53. (doi:10.1007/s00125-013-3071-1)

7 Fenzl A, Itariu BK, Kosi L, Fritzer-Szekeres M, Kautzky-Willer A, Stulnig TM \& Kiefer FW. Circulating betatrophin correlates with atherogenic lipid profiles but not with glucose and insulin levels in insulin-resistant individuals. Diabetologia 201457 1204-1208. (doi:10.1007/s00125-014-3208-x)

8 Fu Z, Berhane F, Fite A, Seyoum B, Abou-Samra AB \& Zhang R. Elevated circulating lipasin/betatrophin in human type 2 diabetes and obesity. Scientific Reports 20144 5013. (doi:10.1038/srep05013)

9 Ebert T, Kralisch S, Hoffmann A, Bachmann A, Lössner U, Kratzsch J, Blüher M, Stumvoll M, Tönjes A \& Fasshauer M. Circulating angiopoietin-like protein 8 is independently associated with fasting plasma glucose and type 2 diabetes mellitus. Journal of Clinical Endocrinology and Metabolism 201499 E2510-E2517. (doi:10.1210/ jc.2013-4349)

10 Ebert T, Stepan H, Schrey S, Kralisch S, Hindricks J, Hopf L, Platz M, Lossner U, Jessnitzer B, Drewlo S et al. Serum levels of irisin in gestational diabetes mellitus during pregnancy and after delivery. Cytokine 201465 153-158. (doi:10.1016/j.cyto.2013.11.009)

11 Ebert T, Hindricks J, Kralisch S, Lossner U, Jessnitzer B, Richter J, Blüher M, Stumvoll M \& Fasshauer M. Serum levels of fractalkine are associated with markers of insulin resistance in gestational diabetes. Diabetic Medicine 201431 1014-1017. (doi:10.1111/dme.12451)

12 American Diabetes Association. Diagnosis and classification of diabetes mellitus. Diabetes Care 201236 S67-S74. (doi:10.2337/dc13-S067)

13 Matthews DR, Hosker JP, Rudenski AS, Naylor BA, Treacher DF \& Turner RC. Homeostasis model assessment: insulin resistance and $\beta$-cell function from fasting plasma glucose and insulin concentrations in man. Diabetologia 198528 412-419. (doi:10.1007/BF00280883)

14 Zhang Y, Li R, Meng Y, Li S, Donelan W, Zhao Y, Qi L, Zhang M, Wang $\mathrm{X}$, Cui $\mathrm{T}$ et al. Irisin stimulates browning of white adipocytes 
through mitogen-activated protein kinase p38 map kinase and erk map kinase signaling. Diabetes 201463 514-525. (doi:10.2337/db13-1106)

15 Quagliarini F, Wang Y, Kozlitina J, Grishin NV, Hyde R, Boerwinkle E, Valenzuela DM, Murphy AJ, Cohen JC \& Hobbs HH. Atypical angiopoietin-like protein that regulates angptl3. PNAS 2012109 19751-19756. (doi:10.1073/pnas.1217552109)
16 Zhang Y \& Scarpace PJ. The role of leptin in leptin resistance and obesity. Physiology \& Behavior 200688 249-256. (doi:10.1016/ j.physbeh.2006.05.038)

17 Fisher FM, Chui PC, Antonellis PJ, Bina HA, Kharitonenkov A, Flier JS \& Maratos-Flier E. Obesity is a fibroblast growth factor 21 (fgf21)-resistant state. Diabetes 201059 2781-2789. (doi:10.2337/db10-0193)

Received 27 September 2014

Revised version received 15 March 2015

Accepted 7 April 2015 